\title{
Decreased serum biochemical markers of muscle origin in patients with ankylosing spondylitis
}

\author{
Erik J Giltay, Dirkjan van Schaardenburg, Louis J G Gooren, Piet J Kostense, \\ Ben A C Dijkmans
}

\begin{abstract}
Objectives-There is a lack of unanimity about (increased) serum levels of creatine kinase $(\mathrm{CK})$ in patients with ankylosing spondylitis (AS), perhaps because of the inclusion of inappropriate controls. Therefore, serum levels of biochemical markers of muscle origin were assessed in AS patients compared with controls.

Methods-In a comparative study serum levels of sarcoplasmic proteins indicating muscle cell leakage, creatinine, and $\mathrm{C}$ reactive protein (CRP) were measured. Fifty eight AS patients with a mean disease duration of 22 (SD 11) years and 58 age and sex matched controls (without back complaints) were included.

Results-Lower serum levels in AS patients compared with controls were found for CK (mean (SD): 46 (21) $v 76$ (44) IU/1; $\mathrm{p}<0.001)$, aldolase $(0.43(0.36) v 0.58(0.32)$ IU/1; $p=0.001)$, creatinine $(91$ (13) $v 96$ (11) $\mu \mathrm{mol} / 1 ; \mathrm{p}=0.02)$, alanine aminotransferase (2.8 (1.5) $v 4.1(2.9) \quad \mathrm{IU} / \mathrm{l} ; \mathrm{p}=0.001)$ and aspartate aminotransferase $(7.0(2.7) v 8.4$ (3.5) IU/1; $p=0.02)$. Also the lean body mass, as estimated by a formula using height, weight, age and sex, showed lower values in patients versus controls (56 (9) $v$ 59 (9) $\mathrm{kg} ; \mathrm{p}=0.004)$, but creatinine clearance (by Cockcroft and Gault formula) was not different $(p=0.48)$. Partial correlation coefficients adjusted for age and sex showed that CRP levels correlated negatively with CK and aldolase levels in AS patients $(r=-0.48, \mathrm{p}<0.001$ and $r=-0.37$, $\mathrm{p}=0.005$, respectively).

Conclusion-Serum levels of biochemical markers of muscle origin were lower in AS patients compared with controls. Patients with active AS, as reflected by high CRP levels, may have an increased protein degradation, predominantly in skeletal muscle.

(Ann Rheum Dis 1999;58:541-545)
\end{abstract}

Ankylosing spondylitis (AS) is a chronic inflammatory disease that primarily affects the sacroiliac joints and the spine. Frequently, it is accompanied by asymmetric arthritis of peripheral joints, uveitis anterior, and other extraspinal manifestations. There is uncertainty whether skeletal muscle is directly involved in the inflammatory process of AS, because muscle changes may also be a consequence of disuse attributable to the pain associated with joint inflammation. Proteins of muscle origin are continually degraded and replaced every one or two weeks. ${ }^{1}$ Among those muscle proteins are the intracellular sarcoplasmic enzymes, such as creatine kinase (CK), aldolase, alanine aminotransferase (ALT) and aspartate aminotransferase (AST), which may circulate in peripheral blood because of muscle membrane vulnerability and leakage. Serum levels of these enzymes may be indicative of muscle mass. CK, which catalyses the reversible phosphorylation of creatine by ATP as a quickly withdrawable energy reserve, is found in many tissues, but is mainly concentrated in skeletal muscle, brain and heart. Aldolase is responsible for the conversion of fructose-1,6biphosphate into glyceraldehyde-3-phosphate and dihydroxyacetone phosphate in the glycolytic pathway. ${ }^{2}$ Aldolase is rather specific for skeletal muscle, but is also found in liver, heart, brain, and other tissues. AST and ALT are well known markers of liver disease, but these enzymes, together with creatinine, are also derived from skeletal muscle. ${ }^{3}$

Conflicting data have been published as to serum levels of biochemical markers of muscle origin in patients with AS. In a study by Calin ${ }^{4}$ increased CK levels were found in 43 patients with AS compared with 82 controls, among whom were an unspecified number of patients with polymyalgia rheumatica and rheumatoid arthritis. These latter diseases are known to be associated with reduced CK levels, ${ }^{56}$ and may, therefore, be less appropriate control conditions. Increased AS disease activity, measured through finger to floor distance, was negatively associated with CK levels. ${ }^{4}$ Moreover, 30 patients with AS again showed increased CK levels compared with 22 controls, who were patients with spondylosis and lumbar disc degeneration. ${ }^{7}$ In uncontrolled studies, 5 of 31 $(16 \%),{ }^{8} 2$ of $19(11 \%),{ }^{9}$ or none of $10^{10}$ patients with AS showed increased CK levels against normal reference values. A small ${ }^{11}$ and a large study ${ }^{5}$ did not show a significant difference in CK levels between patients with AS and controls. In the larger study, the 103 controls were all patients with non-inflammatory arthropathies, yet included patients with low back pain. ${ }^{5}$ Taken together, these studies have demonstrated contradictory data of muscle enzyme levels in patients with AS. The aim of our study was to compare serum levels of CK and other biochemical markers, known to be related to skeletal muscle, in AS patients versus carefully selected, age and sex matched controls, without inflammatory rheumatic disease or low back pain.

\section{Methods}

Male or female patients $\geqslant 18$ years old, fulfilling the New York 1984 criteria for definite AS, ${ }^{12}$ and with radiological involvement of the spine defined by $\geqslant 1$ syndesmophyte on a radiograph were included. For every AS patient a control subject was selected, of the same sex, and not 


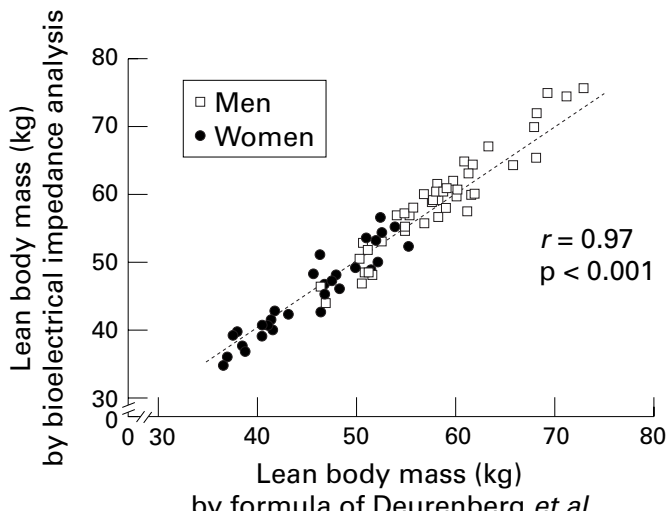

by formula of Deurenberg et al

Figure 1 Scatter plot showing the association between LBM using the formula of Deurenberg et al ${ }^{19}$ and the LBM estimated by $B I A^{20}$ in 44 healthy men and 30 healthy women. Spearman's correlation coefficient is given, as well as a dotted line of equality on which all points would lie if the two estimates gave the same results.

more than two years older or younger. Controls were either members of the healthy clinic staff,
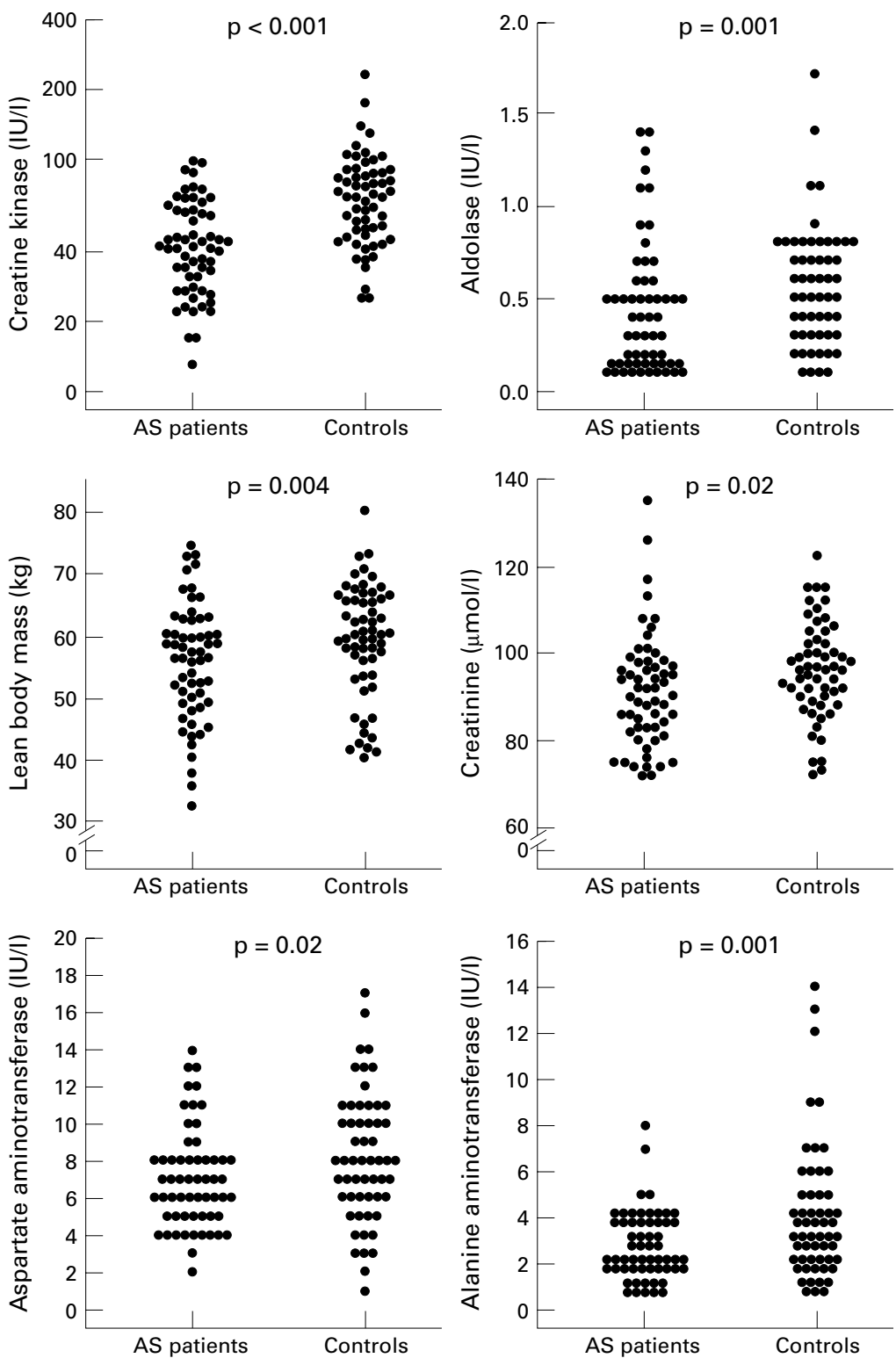

Figure 2 Serum levels of creatine kinase (on a logarithmic scale), aldolase, creatinine, aspartate aminotransferase and alanine aminotransferase, and the estimated lean body mass by a formula of Deurenberg et al, ${ }^{19}$ in 58 patients with ankylosing spondylitis compared with 58 age and sex matched controls. The $p$ values were assessed by t tests for paired samples. or were outpatients with soft tissue rheumatism, but without complaints of the back. The subjects were originally recruited to study sex steroid hormonal levels. ${ }^{13}$ The current mean age of AS patients was 48 years (range 28 to 70 ) and of controls 48 (28 to 72). The body mass index $\left(\mathrm{BMI}=\right.$ weight $/$ height $\left.^{2}\right)$ was calculated in all subjects. None of the subjects had concomitant endocrine, cardiac disease, neoplastic or immune disease, or used sex steroid hormones, anti-androgenic medication, or corticosteroids during the past four weeks. Two male patients with AS (as well as their two matched controls) were excluded from the present analyses, one because of known kidney failure and one because of an intramuscular injection with corticosteroids two weeks before the blood sampling. Informed consent was obtained from all subjects, and the study was approved by the ethical review board.

Non-fasting blood samples were obtained before noon, to assess CK (using a kinetic method, normal range for men $<130 \mathrm{IU} / 1$ and for women $<110 \mathrm{IU} / 1$ ), aldolase (using a kinetic method, normal range $<7.6 \mathrm{IU} / 1)$, creatinine (using the calorimetric Jaffé method, normal range $<124 \mu \mathrm{mol} / \mathrm{l}$ ), ${ }^{14}$ AST (using a kinetic method, normal range $<25 \mathrm{IU} / \mathrm{l}$ ) and ALT (using a kinetic method, normal range for $<35$ IU/1). As serum enzyme levels might be decreased as a consequence of an increased glomerular filtration rate, ${ }^{15}$ we estimated the creatinine clearance rates using the Cockcroft and Gault formula. ${ }^{16}$ The current use of medication was recorded, and total energy of food intake was estimated by a validated Dutch semiquantitative food frequency questionnaire. ${ }^{17}$

As CK levels may be a marker of muscle mass, we estimated the lean body mass (LBM) by sex specific formula using weight and height. In a separate group of healthy subjects (44 men and 30 women) with a mean age of 27 year (range 16-43), we validated the LBM estimation by formula of Hume, ${ }^{18}$ which have previously been used in a study on CK levels in rheumatoid arthritis, ${ }^{6}$ and of Deurenberg et al ${ }^{19}$ by comparing its values to LBM assessed by bioelectrical impedance analysis (BIA 101/S, RJL Systems, Detroit, MI). ${ }^{20}$ We used baseline data from subjects who were included in studies on the effects of sex hormone administration. ${ }^{21}$ The BIA method, which has been validated by the underwater weighing reference method, ${ }^{22}$ is based on the conductivity of an electric current by the electrolytes present in the lean tissues. Subjects were placed in a supine position with the limbs abducted from the body. Four electrodes were placed to measure whole body resistance and reactance of the electric current. LBM was calculated with use of the manufacturer's equations. Spearman's correlation coefficients for the LBM estimated by BIA was $0.95(p<0.001)$ when correlated with the prediction from the formula of Hume, and was $0.97(p<0.001)$ when correlated with the prediction from the formula of Deurenberg et al (fig 1). A strong correlation was, however, guaranteed because of the wide range of LBM and because weight and height are part of the 
Table 1 Intercorrelation data of biochemical serum markers of skeletal muscle in AS patients and controls

\begin{tabular}{|c|c|c|c|c|}
\hline & $\begin{array}{l}\text { Aldolase } \\
\text { (IU/l) }\end{array}$ & $\begin{array}{l}\text { Creatinine } \\
\text { ( } \mu \text { molll) }\end{array}$ & $A S T(I U / l)$ & $A L T(I U / l)$ \\
\hline \multicolumn{5}{|l|}{ AS patients $(n=58)$} \\
\hline $\mathrm{CK}(\mathrm{IU} / \mathrm{l})$ & $0.30(0.03)$ & $0.04(0.74)$ & $0.28(0.03)$ & $-0.17(0.19)$ \\
\hline Aldolase (IU/l) & & $0.14(0.30)$ & $0.32(0.02)$ & $0.26(0.047)$ \\
\hline Creatinine $(\mu \mathrm{mol} / \mathrm{l})$ & & & $-0.06(0.66)$ & $0.23(0.08)$ \\
\hline AST (IU/1) & & & & $0.32(0.02)$ \\
\hline \multicolumn{5}{|l|}{ Controls $(n=60)$} \\
\hline $\mathrm{CK}(\mathrm{IU} / \mathrm{l})$ & $0.24(0.09)$ & $0.18(0.19)$ & $0.32(0.02)$ & $0.15(0.28)$ \\
\hline Aldolase (IU/l) & & $-0.26(0.06)$ & $0.38(0.005)$ & $0.48(<0.001)$ \\
\hline Creatinine $(\mu \mathrm{mol} / \mathrm{l})$ & & & $-0.06(0.69)$ & $-0.03(0.83)$ \\
\hline AST (IU/1) & & & & $0.60(<0.001)$ \\
\hline
\end{tabular}

Values are the partial correlation coefficients ( $\mathrm{p}$ value), adjusted for age and sex.

formulas by all techniques. The mean difference (95\% confidence intervals) for the estimate and BIA was $-2.4 \mathrm{~kg}(-3.3$ to -1.4$)$ for the formula of Hume, and was $-0.3 \mathrm{~kg}(-0.8$ to 0.3$)$ for the formula of Deurenberg et al. The 95\% limits of agreement as described by Bland and Altman, ${ }^{23}$ were -10.0 to $5.3 \mathrm{~kg}$ for the formula of Hume and -4.8 to $5.0 \mathrm{~kg}$ for the formula of Deurenberg et al. Thus, the formula of Hume may systematically underestimate the LBM, which was especially evident in men. Furthermore, the lack of agreement of the formula of Hume with BIA may be because of the inclusion of patients with several disorders and the absence of a "gold standard" technique measuring LBM. ${ }^{18}$ To estimate LBM in our patients with AS we used the formula of Deurenberg et $a l^{19}$ (with LBM in $\mathrm{kg}$, body height in $\mathrm{m}$, body weight in $\mathrm{kg}$, age in years, and sex $=1$ for men and $\operatorname{sex}=0$ for women):

$\mathrm{LBM}=\left(1-\left(\left(1.20 \times\left(\right.\right.\right.\right.$ weight $/$ height $\left.^{2}\right)+0.23$ $\times$ age $-10.8 \times$ sex -5.4$) / 100)) \times$ weight

STATISTICAL ANALYSIS

Variables with distributions that were skewed to the right (aldolase, CK and CRP) were logarithmically transformed before analysis to approximately normalise their distributions. A paired samples $t$ test was used for inter-group comparisons. A $t$ test for independent samples or an analysis of covariance (ANCOVA), to adjust for age, were used to compare variables in different groups of patients. Values were correlated using partial correlation coefficients to adjust for age and sex, or other potential confounding variables. If aldolase or CRP levels were below the lower limit of detection (0.1 $\mathrm{IU} / 1$ and $1 \mathrm{mg} / \mathrm{l}$, respectively) those values were used. A two sided $\mathrm{p}<0.05$ was considered statistically significant. The software used was SPSS for Windows 7.0 (Chicago, IL).

\section{Results}

Forty eight male and 10 female AS patients (all white) and 48 male and 10 female controls (56 white) were included in the study. One female control had an Indonesian father and Dutch mother, while another female control was of Indonesian origin herself. The mean (SD) disease duration was 22 (11) years. The current daily medication of AS patients consisted of non-steroidal anti-inflammatory drugs (NSAID, $\mathrm{n}=39$ ) or second line antirheumatics $(n=17)$. Fourteen AS patients used no medication at all. Controls were either healthy $(n=30)$, or had complaints of osteoarthritis $(n=9)$, painful shoulders $(n=8)$, aspecific myalgia $(n=4)$, or other non-inflammatory peripheral musculoskeletal complaints $(n=7)$. Patients did not differ from controls with respect to age (mean (SD): 48 (10) v 48 (10) year), BMI (25.6 (3.4) ข $26.0(3.2) \mathrm{kg} / \mathrm{m}^{2}$ $\mathrm{p}=0.53$ ), and the estimated glomerular filtration rate $(97(20) v 99$ (24) $\mathrm{ml} / \mathrm{min} ; \mathrm{p}=0.48)$. Neither the glomerular filtration rate nor any biochemical marker of muscle origin did significantly differ in 44 patients using NSAIDs compared with 14 not using NSAIDs ( $p>0.33$ for all), but CRP levels were slightly higher in the patients using NSAIDs compared with those not using NSAIDs (geometric mean: 12.6 v $6.5 \mathrm{mg} / \mathrm{l}, \mathrm{p}=0.06)$. The number of alcohol consumptions and the total energy of food intake per day did not differ between AS patients and controls $(\mathrm{p}=0.34$ and $\mathrm{p}=0.68$ ).

Patients with AS had decreased serum levels of CK, aldolase, creatinine, AST and ALT levels compared with their matched controls (fig 2). Moreover, patients with AS had a decreased LBM compared with controls (55.8 (9.4) v $59.2(9.0) \mathrm{kg} ; \mathrm{p}=0.004)$. Patients with AS also had both a lower height (mean (SD) 1.74 (0.10) v $1.77(0.08) \mathrm{m} ; \mathrm{p}=0.005)$ and weight (77 (13) $v 83$ (13) kg; $\mathrm{p}=0.03$ ) compared with controls. When 44 patients with AS using NSAIDs or second line antirheumatics were excluded, serum levels of CK $(p=0.006)$ and ALT $(p=0.06)$, as well as the LBM $(p=0.07)$ were still largely significantly decreased in

Table 2 Intercorrelation data of biochemical serum markers of skeletal muscle and possible determinants in AS patients and controls

\begin{tabular}{|c|c|c|c|c|c|}
\hline & Age (y) & $B M I\left(k g / m^{2}\right)$ & $\begin{array}{l}\text { Lean body mass } \\
(\mathrm{kg})\end{array}$ & $C R P(m g / l)$ & $\begin{array}{l}\text { Disease duration } \\
(y)\end{array}$ \\
\hline \multicolumn{6}{|l|}{ AS patients $(n=58)$} \\
\hline $\mathrm{CK}(\mathrm{IU} / \mathrm{l})$ & $-0.09(0.49)$ & $-0.05(0.70)$ & $-0.02(0.89)$ & $-0.48(<0.001)$ & $0.03(0.82)$ \\
\hline Aldolase (IU/1) & $0.10(0.47)$ & $0.15(0.26)$ & $0.14(0.31)$ & $-0.37(0.005)$ & $0.15(0.26)$ \\
\hline Creatinine $(\mu \mathrm{mol} / \mathrm{l})$ & $0.45(<0.001)$ & $0.26(0.06)$ & $0.43(0.001)$ & $-0.08(0.56)$ & $-0.22(0.10)$ \\
\hline $\operatorname{AST}(\mathrm{IU} / \mathrm{l})$ & $-0.05(0.72)$ & $-0.11(0.43)$ & $-0.06(0.65)$ & $0.02(0.86)$ & $0.01(0.96)$ \\
\hline ALT (IU/1) & $-0.20(0.14)$ & $0.17(0.19)$ & $0.34(0.01)$ & $0.02(0.84)$ & $-0.10(0.45)$ \\
\hline Disease duration (y) & $0.63(<0.001)$ & $-0.17(0.21)$ & $-0.14(0.32)$ & $-0.23(0.09)$ & - \\
\hline \multicolumn{6}{|l|}{ Controls $(n=60)$} \\
\hline $\mathrm{CK}(\mathrm{IU} / \mathrm{l})$ & $-0.36(0.006)$ & $0.29(0.03)$ & $0.15(0.26)$ & $-0.08(0.56)$ & - \\
\hline Aldolase (IU/1) & $0.02(0.88)$ & $0.27(0.05)$ & $0.25(0.07)$ & $0.07(0.62)$ & - \\
\hline Creatinine $(\mu \mathrm{mol} / \mathrm{l})$ & $0.23(0.08)$ & $-0.07(0.60)$ & $-0.21(0.12)$ & $0.00(0.98)$ & - \\
\hline AST (IU/l) & $-0.28(0.04)$ & $0.32(0.02)$ & $0.32(0.02)$ & $0.04(0.76)$ & - \\
\hline ALT (IU/1) & $-0.10(0.48)$ & $0.40(0.003)$ & $0.33(0.01)$ & $0.09(0.52)$ & - \\
\hline
\end{tabular}

Values are the partial correlation coefficients ( $\mathrm{p}$ value), adjusted for age and sex, or adjusted for sex only when correlated with age. The lean body mass is estimated by the formula of Deurenberg et al. ${ }^{19}$ 

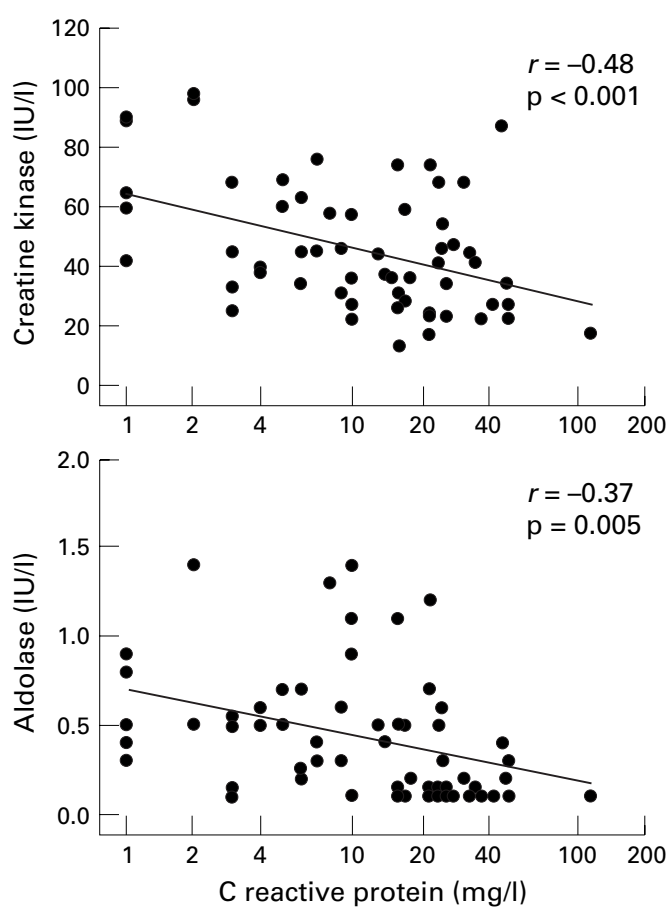

Figure 3 Scatter plot showing the association between $C$ reactive protein level on a logarithmic scale and serum creatine kinase and aldolase in 58 patients with AS (in 48 men and 10 women). Partial correlation coefficients, adjusted for age and sex, and univariate regression lines are given.

patients as compared with their matched controls. When 30 patients with AS were compared with the 30 "healthy" matched controls only, differences were similar and remained largely significant for serum levels of CK $(\mathrm{p}<0.001)$ and ALT $(\mathrm{p}=0.07)$. Intercorrelation data adjusted for sex and age of serum biochemical markers are shown in table 1 ; additional adjustments for LBM, BMI or CRP (in AS patients only; normal or increased, that is, $\geqslant 10 \mathrm{ng} / \mathrm{ml}$ ) in partial correlations did not importantly influence any correlation coefficient, neither in AS patients nor in controls (data not shown). Correlation coefficients with possible determinants of skeletal muscle are given in table 2 . In AS patients, but not in controls, strong negative correlations between CRP levels and either CK and aldolase levels were found (table 2 and fig 3). In AS patients, CRP levels were not significantly correlated with LBM or BMI $(r=0.21, \mathrm{p}=0.12$ and $r=$ $-0.05, p=0.70$, respectively). Disease duration was strongly and positively correlated with age (table 2). When comparing the tertile with the shortest disease duration with that of the longest disease duration (adjusted for age in a ANCOVA), no significant differences were found for the serum biochemical markers of muscle origin, yet lower mean creatinine level $(p=0.04)$ and LBM $(p=0.06)$ were found in late stage AS.

\section{Discussion}

This study provides evidence for decreased circulating markers of skeletal muscle in patients with AS, which seems to represent muscle wasting. In addition, inverse correlations were found between CRP levels and CK and aldolase levels in AS patients, which was reported previously for CK. ${ }^{5}$ Our results partly contradict earlier studies, which reported raised, ${ }^{7-9}$ or normal ${ }^{510}{ }^{11} \mathrm{CK}$ levels. In the past this has even led to the speculation on a pathogenetic role of skeletal muscle in certain manifestations of $\mathrm{AS}^{24}$ The observed discrepancy may have been caused by the lack of controls ${ }^{8-10}$ or the inclusion of less appropriate controls. $^{5} 711$ Muscle biopsy and electromyography studies in patients with AS demonstrated skeletal muscle disease with neuropathic features, ${ }^{102}$ myopathic features, ${ }^{7}{ }^{11}$ and non-specific histological changes. ${ }^{79}$ In AS patients with severe spinal deformities, atrophy of type I and type II muscle fibres was found histologically. ${ }^{25}$ Perhaps some of the muscle histological and biochemical findings have been caused by treatment with high dose phenylbutazone or other NSAIDs. ${ }^{26}$

Several explanations may be proposed for the decreased serum levels of sarcoplasmic enzymes and creatinine. Firstly, in a state of chronic disease, the overall breakdown of cell proteins, especially in muscle, may have been increased to provide the essential amino acids required for protein synthesis and energy metabolism. ${ }^{127}$ Hence, a decrease in protein synthesis or an increase in the proteolytic machinery, or both, may be a cause of lower circulating proteins of muscle origin. This idea is consistent with the finding of a negative correlation between sarcoplasmic enzymes and CRP levels. This strong inverse relation may have obscured the inverse correlation between $\mathrm{CK}$ levels and age as well as the positive correlations between CK levels and BMI and LBM, which were found in our controls. Increased levels of CRP, or a concomitant increase of inflammatory cytokines, may lead to an increased encoding of ubiquitin and proteasomes, which are part of an intracellular proteolytic system that degrades the bulk of muscle proteins. ${ }^{127}$ Various disease conditions, such as sepsis, acidosis, infection (for example, AIDS), cancer and burns, have all been shown to increase this ubiquitin-proteasome pathway, and AS may be an additional condition. This suggests that pharmacological suppression of inflammation can help to preserve muscle mass. This idea does not seem to be compatible with the similar levels of biochemical markers of skeletal muscle in AS patients using NSAIDs or second line antirheumatics compared with those not using these medication. This may be explained, however, by the higher disease activity in patients using such medication, as documented by their higher geometric mean CRP level.

Secondly, immobilisation is an important factor leading to muscle atrophy. In patients with AS, low physical activity may be attributable to stiffness and pain. Thirdly, sex hormones, and especially anabolic steroids, are important determinants of muscle mass. ${ }^{28}$ In the same study subjects we have shown that there are no significant differences in $17 \beta$ estradiol and testosterone levels between AS patients and controls. ${ }^{13}$ However, data on glucocorticoid, growth hormone, or insulinlike growth factor-1 metabolism are lacking. 
Fourthly, nutrition and food supply may influence muscle protein synthesis and breakdown. Total energy of food intake, however, did not differ between AS patients and controls.

Earlier studies reported increased alkaline phosphatase and $\gamma$-glutamyltransferase levels, as well as increased AST and ALT levels in a proportion of patients with AS. ${ }^{49}{ }^{30}$ We did, however, not find any evidence of liver disease. Creatinine is formed in the skeletal muscle and is excreted by the kidneys, mainly by glomerular filtration. Low serum creatinine levels may result from a decreased muscle mass and debilitation, but also from severe hepatic disease, ${ }^{31}$ inadequate dietary protein, or increased glomerular filtration. In this respect it is noteworthy that the glomerular filtration rate using the Cockcroft and Gault estimate ${ }^{16}$ did not differ between AS patients and controls. Also, the use of NSAIDs in our AS patients was not associated with impaired glomerular filtration rate, which is a side effect of chronic NSAID use. $^{32}$ Assuming a comparable glomerular filtration, the lower serum creatinine in AS patients versus controls may have resulted from a lower muscle mass. A limitation of our study was the use of non-fasting serum samples, which may be of concern for aldolase measurements. Moreover, the estimation of LBM based on height, weight, age and sex may have limited value, because height may be underestimated because of spinal flexion deformities in AS and the assumptions on which the formula are based may not apply to AS patients. The shorter height of patients compared with controls was, however, paralleled by a lower weight. There may be several reasons for the rather poor associations found between muscle biochemical markers and LBM. Firstly, we used a crude estimate for LBM, which represents the fat free compartment and is composed not only of muscle mass, but also of bone mass and extracellular water. Secondly, serum levels of muscle enzymes are a result of both production and clearance rates, the latter is thought to be upregulated in states of chronic inflammation. Thirdly, these markers also originate from other tissues than skeletal muscle. Muscle tissue, however, is the common source of the biochemical markers that were assessed in this study.

In conclusion, circulating levels of several muscle enzymes and creatinine are reduced in patients with AS compared with controls. These data can be added to the clinical, electromyographical, and histological evidence for myopathy in AS. Our data suggest that muscle wasting is a consequence of disease activity, which may be mediated through an increased protein degradation in skeletal muscle. This is also in line with the absence of inflammatory cells in muscle biopsies. ${ }^{9} 1025$ Future studies on myopathy with careful measurement of muscle mass are needed, to usefully extend our biochemical data to the concept of muscle wasting in AS.

We are indebted to the staff of the laboratory department of the Jan van Breemen Institute (heads: G M de Gast and R J van de Stadt, PhD) for measurements of biochemical markers. We thank J M H Elbers, Organon Pharmaceuticals, Oss, the Netherlands, for generously providing data on LBM measurements.

1 Mitch WE, Goldberg AL. Mechanisms of muscle wasting. N Engl J Med 1996;335:1897-905.

2 Gamblin SJ, Davies GJ, Grimes JM, Jackson RM, Littlechild JA, Watson HC. Activity and specificity of human aldolases. J Mol Biol 1991;219:573-6.

3 Helzberg JH, Spiro HM. 'LFTs' test more than the liver. JAMA 1986;256:3006-7.

4 Calin A. Raised serum creatine phosphokinase activity in ankylosing spondylitis. Ann Rheum Dis 1975;34:244-8.

5 Sanmartí R, Collado A, Gratacós J, Herrera BE, Font J Cañete JD, et al. Reduced serum creatine kinase activity in inflammatory rheumatic disease. J Rheumatol 1996;23: 310-12.

6 Stucki G, Brühlmann P, Stoll T, Stucki S, Willer B, Michel $B A$. Low serum creatine kinase activity is associated with muscle weakness in patients with rheumatoid arthritis. Rheumatol 1996;23:603-8.

7 Faus-Riera S, Martínez-Pardo S, Blanch-Rubió J, BenitoRuiz P, Duró-Pujol JC, Corominas-Torres JM. Muscle pathology in ankylosing spondylitis: clinical, enzymatic, electromyographic and histologic correlation. J Rheumatol 1991;18:1368-71.

8 Bohan A, Stracner J, Norton S. CPK elevation in the spondylarthropathies. J Rheumatol 1990;17:565-7.

9 Hopkins GO, McDougall J, Mills KR, Isenberg DA Ebringer A. Muscle changes in ankylosing spondylitis. Br J Rheumatol 1983;22:151-7.

10 Carrabba M, Chevallard M, Colombo B, Dworzak F, Mora M, Cornelio F. Muscle pathology in ankylosing spondylitis Clin Exp Rheumatol 1984;2:139-44.

11 Hagberg M, Hagner IM, Bjelle A. Shoulder muscle strength, endurance and electromyographic fatigue in ankylosing spondylitis. Scand J Rheumatol 1987;16:161-5.

12 Van der Linden S, Valkenburg HA, Cats A. Evaluation of diagnostic criteria for ankylosing spondylitis: a proposal for modification of the New York criteria. Arthritis Rheum 1984;27:361-8.

13 Giltay EJ, Popp-Snijders C, van Schaardenburg D, DekkerSaeys AJ, Gooren LJG, Dijkmans BAC. Serum testosterSaeys AJ, Gooren LJG, Dijkmans BAC. Serum testosterone levels are not elevated in patients with

14 Kratz A, Lewandrowski KB. Normal reference laboratory values. N Engl J Med 1998;339:1063-73.

15 Van der Meulen JH, Kuipers H, Drukker J. Relationship between exercise-induced muscle damage and enzyme release in rats. J Appl Physiol 1991;71:999-1004.

16 Cockcroft DW, Gault MH. Prediction of creatine clearance from serum creatinine. Nephron 1976;16:31-41.

17 Feunekes IJ, van Staveren WA, Graveland F, de Vos J, Burema J. Reproducibility of a semiquantitative food frequency questionnaire to assess the intake of fats and cholesterol in The Netherlands. Int J Food Sc Nutr 1995; 46:117-23.

18 Hume R. Prediction of lean body mass from height and weight. J Clin Pathol 1966;19:389-91.

19 Deurenberg P, Weststrate JA, Seidell JC. Body mass index as a measure of body fatness: age-and sex-specific prediction formulas. Br J Nutr 1991;65:105-14.

20 Segal KR, Van Loan M, Fitzgerald PI, Hodgdon JA, Van Itallie TB. Lean body mass estimation by bioelectrical impedance analysis: a four-site cross-validation study. Am J Clin Nutr 1988;47:7-14.

21 Elbers JMH, Asscheman H, Seidell JC, Gooren LJG. Effects of sex steroid hormones on regional fat depots as assessed by magnetic resonance imaging in transsexuals. Am J Physiol 1999;276:E317-25.

22 Broekhoff C, Voorrips LE, Weijenberg MP, Witvoet GA, van Staveren WA, Deurenberg P. Relative validity of different methods to assess body composition in apparently healthy methods to assess body composition in apparently

23 Bland JM, Altman DG. Statistical methods for assessing agreement between two methods of clinical measurement. Lancet 1986;i:307-10.

24 Masi AT. Do sex hormones play a role in ankylosing spondylitis? Rheum Dis Clin North Am 1992;18:153-76.

25 Simmons EH, Graziano GP, Heffner R. Muscle disease as a cause of kyphotic deformity in ankylosing spondylitis. Spine 1991;16 (suppl 8):S351-60.

26 Zuckner J. Drug-induced myopathies. Semin Arthritis Rheum 1990;19:259-68.

27 Tawa NE, Goldberg AL. Protein and amino acid metabolism in muscle. In: Myology: basic and clinical. Engel AG, lism in muscle. In: Myology: basic and clinical. Engel AG, Franzini-Armstrong

28 Bhasin S, Storer TW, Berman N, Callegari C, Clevenger B, Phillips J, et al. The effects of supraphysiologic doses of testosterone on muscle size and strength in normal men. $\mathrm{N}$ Engl J Med 1996;335:1-7.

29 Akesson A, Berglund K, Karlsson M. Liver function in some common rheumatic disorders. Scand J Rheumatol 1980;9: $81-8$.

30 Robinson ACR, Teeling M, Casey EB. Hepatic function in ankylosing spondylitis. Ann Rheum Dis 1983;42:550-2.

31 Takabatake T, Ohta H, Ishida Y, Hara H, Ushiogi Y, Hattori $\mathrm{N}$. Low serum creatinine levels in severe hepatic disease. Arch Intern Med 1988;148:1313-15.

32 Pernerger TV, Whelton PK, Klag MJ. Risk of kidney failure associated with the use of acetaminophen, aspirin, and nonsteroidal antiinflammatory drugs. N Engl J Med 1994; 331:1675-9 [Editorial 1711-12]. 